Brit. Heart F., 1969, 31, 273.

\title{
Incidence and Management of Ventricular Arrhythmias after Acute Myocardial Infarction
}

\author{
E. B. RAFTERY, M. F. REHMAN, D. C. BANKS, AND S. ORAM \\ From the Cardiac Department, King's College Hospital, Denmark Hill, London S.E.5
}

The introduction of continuous electrocardiographic monitoring of patients immediately after acute myocardial infarction has resulted in several publications describing the frequency of arrhythmias and discussing the value of treatment. This paper is a critical assessment of ventricular arrhythmias in 252 such patients.

\section{Patients and Methods}

All patients passed through the Intensive Coronary Care Unit at King's College Hospital during a period of 12 months, and no selection was employed other than the availability of beds. The presence of a recent myocardial infarct was established according to the criteria previously defined for this Unit (Jewitt et al., 1967). All patients underwent electrocardiographic monitoring for at least 72 hours, using "Visomonitors" (Sanborn), with sampling at 15-minute intervals. The first 114 of the patients were also included in a trial of oral propranolol (Balcon et al., 1966).

The following criteria were used in classifying arrhythmias (Table I).

(1) Ventricular ectopic beats-two or more ectopic beats recorded every hour for at least 24 hours, with or without other arrhythmias.

(2) Ventricular tachycardia, uncomplicated, namely one or more bouts with no other significant arrhythmia.

(3) Ventricular fibrillation, uncomplicated, meaning cardiac arrest in ventricular fibrillation in the absence of any preceding significant arrhythmia.

(4) Multiple arrhythmias.

(5) Bundle-branch block.

In common with other authors, agonal arrhythmias have not been included.

The haemodynamic effects of the cardiac infarct and the response to treatment were assessed as follows. In 34 patients the central venous pressure was monitored

Received November 11, 1968. by a line of No. 3 nylon (Portex, Ltd.) passing percutaneously from a peripheral vein to the right atrium or pulmonary artery. A short length of radio-opaque tubing (OPP 160, Portex, Ltd.) was also inserted percutaneously into the femoral artery to allow the arterial pressure to be monitored. Serial estimations of cardiac output were made by a dye dilution technique, drawing blood from the femoral artery through a densitometer (Gilford).

\section{RESULTS}

Of the 252 patients passing through the Unit, 190 were male and 62 female, with an age range from 34 to 82 , the average being 54 . Fifty-eight died during the first 28 days, giving an over-all mortality of 23 per cent, 139 suffered anterior infarction, 85 posterior infarction, 15 both anterior and posterior, and 13 were undetermined. Ventricular arrhythmias were observed in 89 patients $(35 \%)$; the type, frequency, mortality, and site of infarction are shown in Table I.

Ventricular Ectopic Beats. There were 70 patients who showed this arrhythmia, with a mortality of 21 per cent. Analysis of these patients is shown in Table II.

In addition, 38 showed ventricular ectopic beats with no other arrhythmia, and 6 died; 4 of the fatal cases had cardiogenic shock, and 1 developed severe left ventricular failure a few days after admission; the remaining patient died from a dissecting aneurysm of the aorta.

Another 19 patients had ventricular ectopic beats associated with a supraventricular arrhythmia, 2 of whom died. Neither had cardiogenic shock, though both had extensive anterior infarctions.

Seven patients whose major arrhythmia was ventricular tachycardia also showed numerous isolated ventricular ectopic beats. 
TABLE I

INCIDENCE OF VENTRICULAR ARRHYTHMIAS

\begin{tabular}{|c|c|c|c|c|c|c|}
\hline \multirow[b]{2}{*}{ Type } & \multirow[b]{2}{*}{ No. } & \multirow[b]{2}{*}{ Mortality } & \multicolumn{4}{|c|}{ Site of infarction } \\
\hline & & & Anterior & Posterior & $\begin{array}{l}\text { Anterior and } \\
\text { posterior }\end{array}$ & Undetermined \\
\hline $\begin{array}{l}\text { Ventricular ectopic beats with or with- } \\
\text { out other arrhythmias } \\
\text { Ventricular tachycardia, uncomplicated } \\
\text { Ventricular fibrillation, uncomplicated } \\
\text { Multiple arrhythmias } \\
\text { Bundle-branch block Right } \\
\text { Left }\end{array}$ & $\begin{array}{r}70 \\
15 \\
22 \\
8 \\
15 \\
7\end{array}$ & $\begin{array}{r}15(21 \%) \\
5(33 \%) \\
10(45 \%) \\
6(75 \%) \\
5(33 \%) \\
2(29 \%)\end{array}$ & $\begin{array}{r}42 \\
10 \\
16 \\
4 \\
8 \\
3\end{array}$ & $\begin{array}{r}21 \\
4 \\
4 \\
2 \\
5 \\
2\end{array}$ & $\begin{array}{l}2 \\
1 \\
1 \\
0 \\
0 \\
0\end{array}$ & $\begin{array}{l}5 \\
0 \\
1 \\
2 \\
2 \\
2\end{array}$ \\
\hline
\end{tabular}

TABLE II

VENTRICULAR ECTOPIC BEATS

\begin{tabular}{|c|c|c|c|c|c|c|}
\hline \multirow[b]{2}{*}{ Type } & \multirow[b]{2}{*}{ No. } & \multirow[b]{2}{*}{ Mortality } & \multicolumn{4}{|c|}{ Site of infarction } \\
\hline & & & Anterior & Posterior & $\begin{array}{c}\text { Anterior and } \\
\text { posterior }\end{array}$ & Undetermined \\
\hline $\begin{array}{l}\text { Ventricular ectopic beats only } \\
\text { Supraventricular arrhythmia and ven- } \\
\text { tricular ectopic beats } \\
\text { Ventricular tachycardia and ventricu- } \\
\text { lar ectopic beats } \\
\text { Ventricular fibrillation followed by } \\
\text { ventricular ectopic beats }\end{array}$ & $\begin{array}{r}38 \\
19 \\
7 \\
6\end{array}$ & $\begin{array}{l}6(16 \%) \\
2(11 \%) \\
4(59 \%) \\
3(50 \%)\end{array}$ & $\begin{array}{r}23 \\
11 \\
4 \\
4\end{array}$ & $\begin{array}{r}12 \\
6 \\
3 \\
0\end{array}$ & $\begin{array}{l}0 \\
2 \\
0 \\
0\end{array}$ & $\begin{array}{l}3 \\
0 \\
0 \\
2\end{array}$ \\
\hline Totals & 70 & $15(21 \%)$ & 42 & 21 & 2 & 5 \\
\hline
\end{tabular}

Six patients who presented with ventricular fibrillation later showed ventricular ectopic beats.

As might be expected, the proportion of deaths in patients with ventricular ectopic beats associated with ventricular fibrillation and ventricular tachycardia was much higher than in those showing ventricular ectopic beats alone or associated with supraventricular arrhythmias, and was largely responsible for the over-all mortality rate of 21 per cent.

Ventricular ectopic beats, whether isolated or associated with other arrhythmias, were recorded twice as commonly in patients with anterior as in those with posterior infarction, but when the total numbers of anterior and posterior infarcts in each group were considered there was no significant difference. There were 139 patients with anterior and 85 with posterior infarction, and the percentage difference in the two groups was not significant, being only 5 per cent, namely 30 per cent in the anterior and 25 per cent in the posterior infarcts. Of the $\mathbf{4 2}$ patients with anterior infarction and ventricular extrasystoles, 6 also had sinus bradycardia, and 7 had sinus tachycardia. Of the 21 patients with posterior infarction and ventricular ectopic beats, 4 had sinus bradycardia, and 6 had sinus tachycardia.

Ventricular ectopic beats falling on the $T$ wave of a preceding beat (" $R$ on $T$ ") were seen in 13 patients, 8 with anterior and 5 with posterior infarction. Five of these later developed ventricular fibrillation. There were also 12 patients who did not show the " $R$ on $T$ " combination at any time and who developed ventricular fibrillation. Repeated episodes of a ventricular ectopic rhythm which was not rapid were present in 11 patients; in fact it was usually slower than the prevailing sinus rhythm (Fig. 1); 6 of these developed one or more bouts of ventricular fibrillation; 2 were successfully resuscitated but 4 died. Only one of these patients was shocked, and all had anterior infarction.

Treatment. Twenty-seven patients were treated with lignocaine intravenously. Each patient was given an initial dose of $100 \mathrm{mg}$. followed by $1.0 \mathrm{~g}$. in 5 per cent glucose daily for at least 3 days. This regimen was judged successful in suppressing the arrhythmia in 16 (Fig. 2); 20 complained, however, that they felt faint and sleepy for a few minutes after the initial loading dose, but no complications were observed during long-term administration. Haemodynamic observations were made in 4 patients. A single injection of $100 \mathrm{mg}$. lignocaine produced a rise in the mean pressure of the femoral artery in 3 patients and a slight fall in the fourth (Fig. 3). These changes were related to suppression of ectopic 


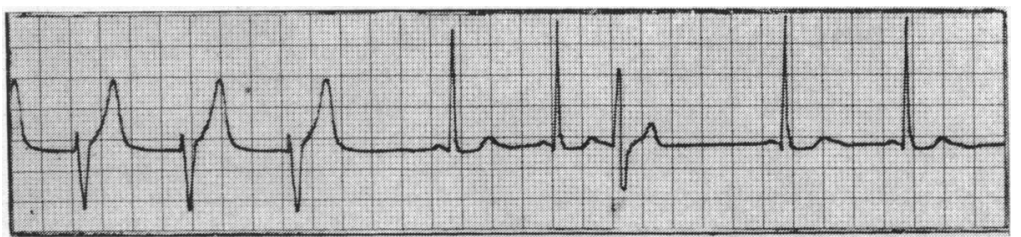

FIG. 1.-Bout of slow ventricular ectopic rhythm. This arrhythmia was observed in 11 patients, of whom 6 died.

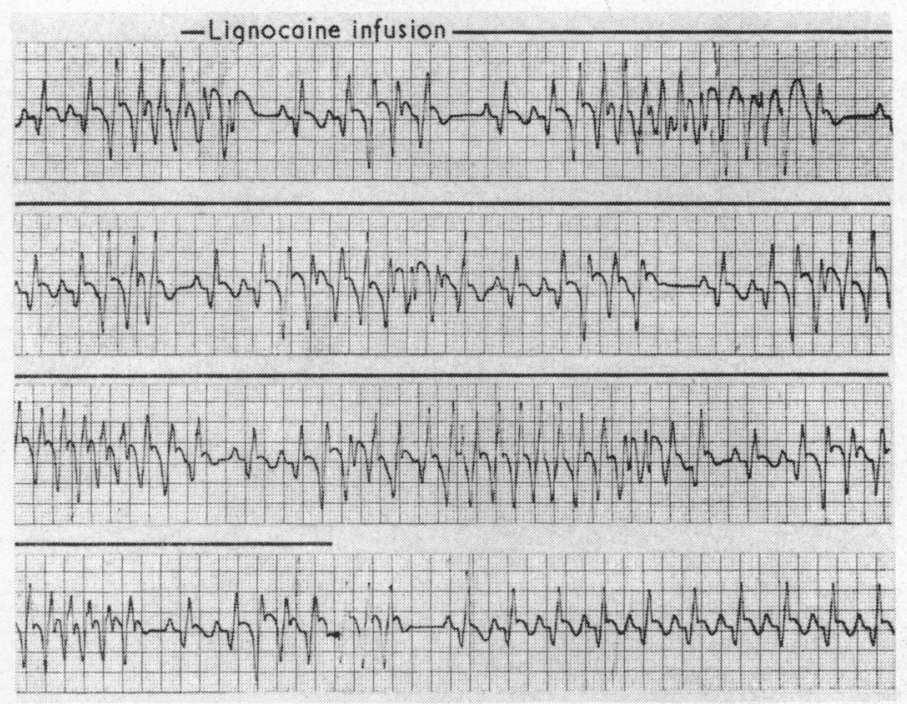

FIG. 2.-Runs of multifocal ectopic beats restored to sinus rhythm by means of $100 \mathrm{mg}$. lignocaine intravenously. The period of the infusion is indicated by the bar.

beats rather than to any direct effects of the drug. In 2 patients there was a concomitant increase in the cardiac output, with a net fall in the systemic resistance and hence a decreased cardiac work-load. However, in 2 patients whose cardiac output was already low, there was a considerable fall in output and rise in systemic resistance after the infusion, and hence an increase in the work-load of the heart.

Prolonged infusion of lignocaine over a period of three days produced no significant change in the cardiac output or mean femoral arterial pressure. In three patients there was a fall in the systemic resistance which rose to normal after stopping the infusion (Fig. 4).

Ventricular Tachycardia. Bouts of ventricular tachycardia during the course of other arrhythmias were experienced by 11 patients, but this was the dominant arrhythmia in 15 others (Table I), and of these 15,5 died. Two patients with posterior infarction developed ventricular tachycardia while they were being paced for complete heart block. In neither case was there any prior evidence of ven- tricular irritability, and the catheter had been in place for more than a week. Neither patient had shown any sign of returning to sinus rhythm when the ventricular tachycardia began. Both developed irreversible ventricular fibrillation in less than 24 hours. A third patient with a posterior infarct had arrested at home, and was moribund on admission and died shortly afterwards. Both patients with anterior infarction who died were severely shocked.

Treatment. In 3 patients the arrhythmia spontaneously reverted to sinus rhythm with occasional ventricular ectopic beats. Of 7 patients treated with lignocaine, 5 rapidly reverted to sinus rhythm. The other 2 proved resistant and also failed to respond to $10 \mathrm{mg}$. propranolol intravenously and to direct-current shock. An intravenous dose of $0.5 \mathrm{~g}$. procainamide brought both back to sinus rhythm, and this was maintained by means of a continuous intravenous infusion of $1.0 \mathrm{~g}$. procainamide every 24 hours for 2 days. Subsequently they were maintained on procainamide orally. Fig. 5 and 6 show the results of haemodynamic observations on 

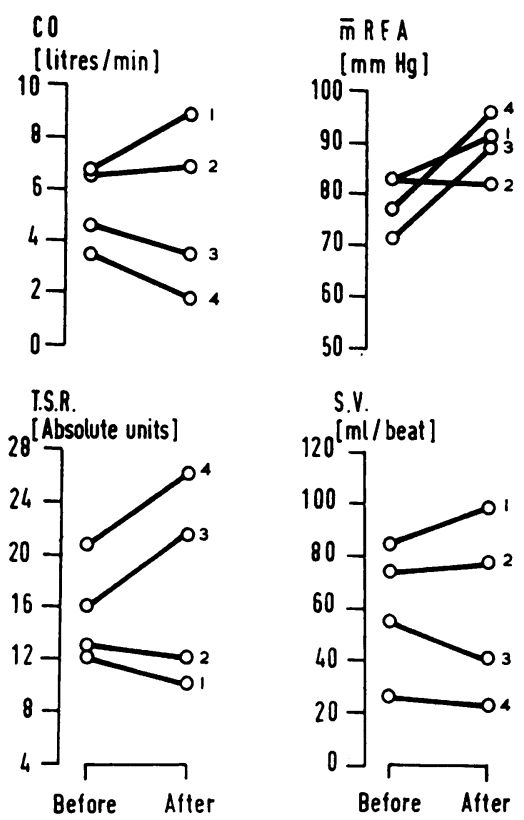

FIG. 3.-Haemodynamic effects of $100 \mathrm{mg}$. of lignocaine intravenously in 4 patients. A fall in cardiac output (CO) with a rise in mean femoral artery pressure ( $\bar{n}$ RFA) was observed in 2 patients ( 3 and 4 ) in whom the initial cardiac output was already low. The resultant increase in total systemic resistance (TSR) implies an increase in the work load of the left ventricle.

these patients. Restoration of sinus rhythm increased the cardiac output and restored the blood pressure to normal. There was no deterioration over the period of prolonged administration.

Ventricular Fibrillation. Ventricular fibrillation was observed in 40 of the 252 patients $(15 \%) ; 22$ of them developed this arrhythmia without previous evidence of other serious arrhythmias, 7 within an hour of admission. Six others had shown sinus tachycardia, 3 of whom had severe cardiogenic shock. Three others had complicating conditions - severe myxoedema, cardiac rupture, and mitral stenosis.

Of the 6 patients with ventricular fibrillation associated with ventricular extrasystoles (Table II), 3 had repeated episodes of ventricular fibrillation and all 3 survived.

Three patients with rapid atrial fibrillation, and therefore not included in Table I, were found to have bouts of ventricular fibrillation which were too short to produce cardiac arrest. The " $R$ on $T$ " combination was not seen in any of them. The atrial fibrillation was abolished and all 3 survived.

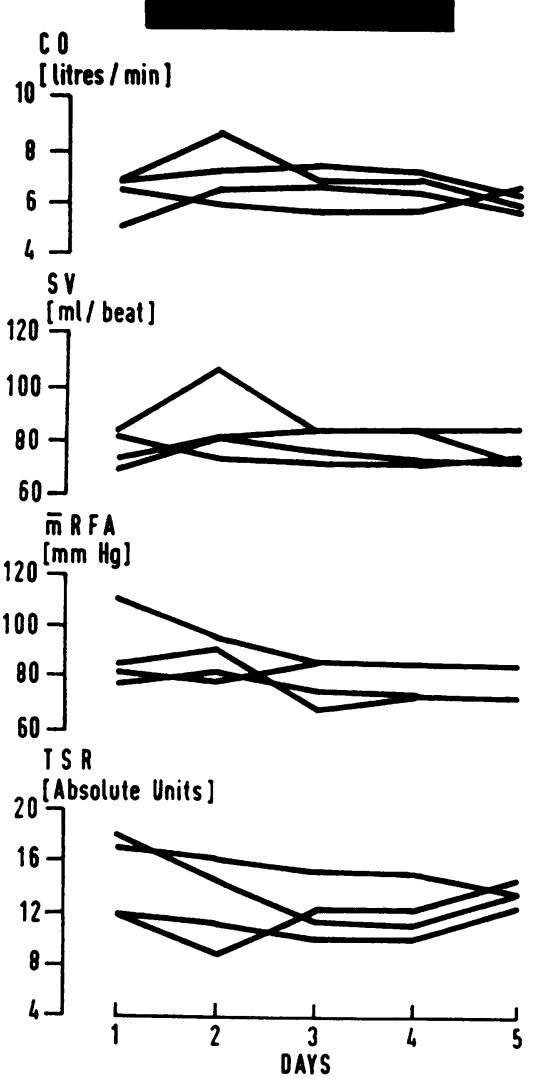

FIG. 4.-Haemodynamic effects of a three-day period of lignocaine infusion. There is some tendency to vasodilatation in 3 patients.

Treatment. The mortality in ventricular fibrillation not associated with other arrhythmias was 45 per cent. Of the 10 patients who died, 5 were readily restored to sinus rhythm by a single directcurrent shock, but could not maintain a satisfactory cardiac output. All 5 had a history of previous infarction; 3 had severe cardiogenic shock and 1 had incidental mild mitral stenosis.

The remaining 5 fatal cases were reverted to sinus rhythm by a direct-current shock, but this could not be maintained. These patients died in asystole which failed to respond to infusions of isoprenaline and calcium. Cardiac pacemaking by means of electrodes applied to the chest also failed to maintain the circulation. In 3 of them pacemaking by means of a needle passed into the myocardium through the chest wall also failed. Right ventricular endocardial pacing was also unsuccessful in 1 patient. All 5 had suffered their first myocardial infarct and were not shocked before they developed ventricular fibrillation. 

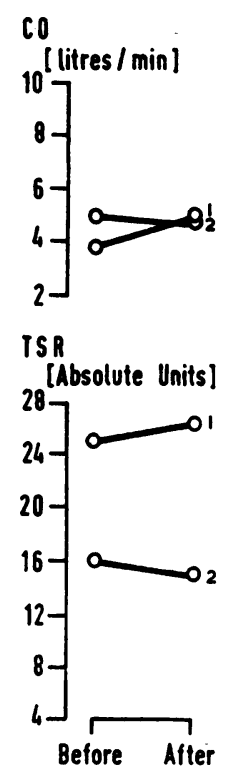
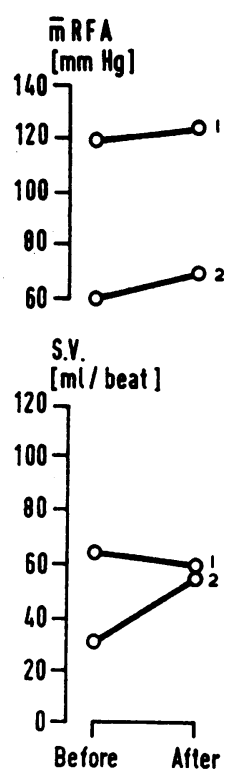

FIG. 5.-Haemodynamic effects of $0.5 \mathrm{~g}$. procainamide intravenously in 2 patients. Unlike lignocaine there is little change in the measured parameters, even though the initial cardiac output was low.

All patients who survived ventricular fibrillation were subsequently treated with lignocaine infusions for at least three days in an attempt to reduce ventricular irritability.

Multiple Arrhythmias. All 8 patients with multiple arrhythmias, both supraventricular and ventricular, were very resistant to treatment. The mortality in this group, 6 of 8, was the highest of any though only 2 had cardiogenic shock.

Treatment. The group was treated by a prolonged trial of lignocaine and procainamide, followed by large doses $(80 \mathrm{mg}$. q.i.d.) of propranolol combined with intramuscular injection of atropine, $1.2 \mathrm{mg}$. 6-hourly, to prevent undue bradycardia. Only 2 survived. Paired pacing (Braunwald et al., 1964) was attempted in 2 patients with rapid ventricular rates, but in neither was the heart rate controlled for more than a few hours.

Bundle-branch Block. Twenty-two patients showed left or right bundle-branch block, and the mortality was 32 per cent. Right bundle-branch block was twice as common as left, and was associated with anterior infarction more frequently than posterior (Table I). Only 2 of the fatal cases had cardiogenic shock.

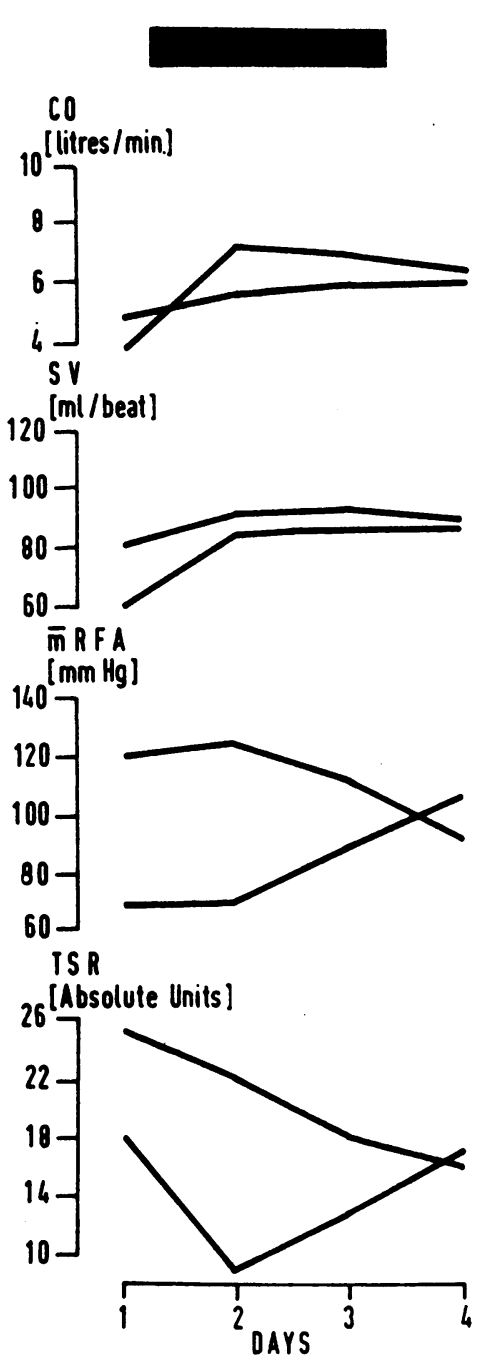

FIG. 6.-Haemodynamic effects of a two-day period of procainamide infusion in 2 patients. There is little change in the measured parameters.

\section{Discussion}

Ventricular ectopic beats are commonly observed after myocardial infarction (Julian, Valentine, and Miller, 1964; Meltzer and Kitchell, 1966; Stock, Goble, and Sloman, 1967).

Ventricular fibrillation is thought to be common in patients with frequent ectopic beats, but this has not been our experience. When ventricular ectopic beats were associated with other ventricular arrhythmias there was a high mortality, but of 38 patients with ectopic beats alone, only 6 died, and in all 6 there was an additional complication such as cardiogenic shock. Of the remaining 32 patients, only 2 


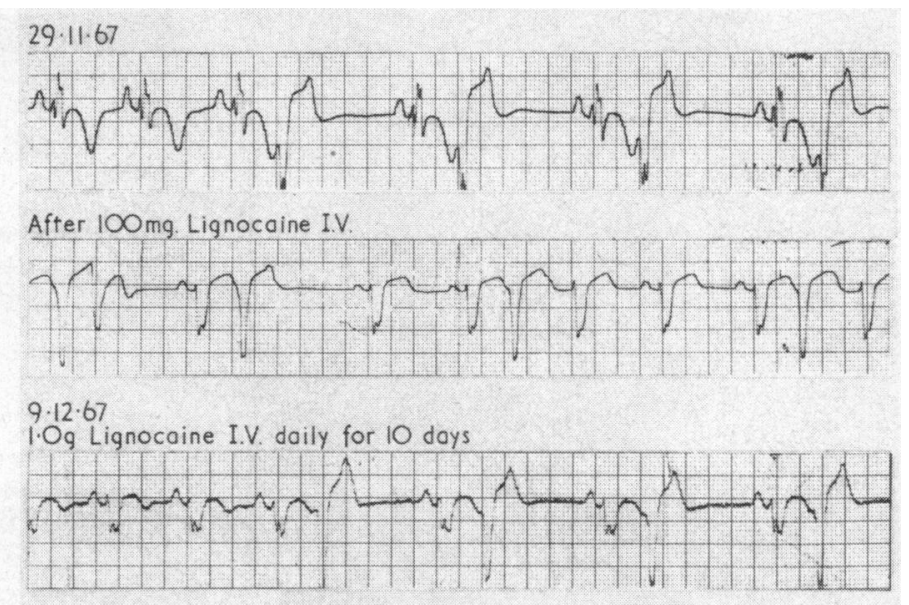

FIG. 7.-Ventricular ectopic beats showing the " $R$ on $T$ " combination. After $100 \mathrm{mg}$. lignocaine intravenously, the ectopic beats were as frequent but fell later on the $T$ wave. After a 10-day period of lignocaine infusion, ectopic beats were as frequent as before and still showed the " $R$ on $T$ " phenomenon. This patient had no episodes of ventricular fibrillation.

developed ventricular fibrillation and both were successfully resuscitated. We entirely agree with Lawrie et al. (1968) that the most urgent therapeutic requirement in ventricular fibrillation is immediate DC shock and that all other therapeutic measures are secondary.

Such findings raise the question of when to treat ventricular ectopic beats. Clearly some attempt should be made to suppress them in patients who have shown other arrhythmias or cardiogenic shock, but even frequent ventricular ectopic beats are not necessarily the cause of the high mortality rate. Smirk and Palmer (1960) suggested that ventricular ectopic beats falling upon the $T$ wave of a preceding sinus beat (" $R$ on $T$ ") are indicative of impending ventricular fibrillation, but this is not necessarily so (Fig. 7). Of more importance, in our experience, ventricular fibrillation is not uncommonly seen in the absence of " $R$ on $T$ ".

When frequent, ectopic beats undoubtedly reduce the cardiac output and systemic blood pressure, and it seems reasonable to regard this effect rather than the risk of ventricular fibrillation as the main reason for suppressive therapy.

Ventricular ectopic beats might be expected to arise either as a result of an ischaemic, highly irritable area of ventricular myocardium acting as an ectopic focus, or as a result of sinus bradycardia with ventricular escape. The latter is not uncommon, and is easily corrected with parenteral atropine; all our patients with a sinus rate of less than $60 / \mathrm{min}$. were so treated.

Whenever frequent ectopic beats were monitored steps were taken to suppress them. Lignocaine is thought to be the drug of choice since it causes less depression of myocardial contractility than procainamide (Harrison, Sprouse, and Morrow, 1963). Our experience of single injections and prolonged administration of lignocaine has confirmed that it is relatively innocuous, but it is not so uniformly successful in suppressing ventricular ectopic beats as might be thought (Gianelly et al., 1967; Spracklen et al., 1968). It caused considerable depression of the cardiac output in 2 patients whose outputs were already low. Furthermore, it is known to be epileptogenic (Gianelly et al., 1967), and one of our patients suffered several fits after intravenous lignocaine. We have used procainamide on a number of occasions when lignocaine has failed, and our small number of haemodynamic studies suggests that it has earned an undeserved reputation for depression of myocardial contractility. It has the advantage of oral administration.

Sinus bradycardia and tachycardia with ventricular ectopic beats were seen as commonly in patients with anterior infarcts as with posterior. Eleven patients with anterior infarction developed a slow ventricular ectopic arrhythmia, and the mortality among these was high. It seems that this arrhythmia should be suppressed at the earliest opporunity.

Though ventricular tachycardia is not infrequent after myocardial infarction, it is not commonly the dominant arrhythmia. Each episode usually resolves spontaneously (Fluck et al., 1967). When it persists, lignocaine has usually abolished this 
arrhythmia, and in resistant patients we have had good results from procainamide. It is of interest that ventricular tachycardia supervened in 2 of our patients with complete heart block. This corresponds with the experience of others during elective pacing for chronic heart block (Harris et al., 1968). The frequency of ventricular fibrillation is difficult to assess, and in at least one series has been as low as 1 per cent (Lown et al., 1967). In our series the frequency was 15 per cent. The reasons for such variable figures have been discussed by Lawrie et al. (1958). Ventricular fibrillation in the absence of other arrhythmias is not uncommon and constituted 22 of our 40 examples. Lawrie et al. (1968) have pointed out that it is the time of onset of the ventricular fibrillation that chiefly determines whether it is preceded by ventricular extrasystoles or ventricular tachycardia. If the fibrillation develops early it is not usually preceded by other arrhythmias but is commonly so if it comes on after 24 hours.

Of our 22 patients with this arrhythmia as an isolated finding, 6 had cardiogenic shock; 6 others had shown no more sinister sign of impending cardiac arrest than a persistent sinus tachycardia. Patients who died showed a clear division into those with a history of multiple infarction who could not maintain a cardiac output even when restored to sinus rhythm, and those who had a short history of myocardial ischaemia and could not be restored to sinus rhythm for any length of time. One-half of the patients with uncomplicated ventricular fibrillation who died (5 of 10) had sustained their first infarct and were not shocked before the onset of fibrillation. While the first group of patients might not be expected to make a recovery, the failure of the second group to respond to any form of treatment is difficult to explain. It may be that a short period of cardiopulmonary bypass would enable the heart to become less irritable and more likely to maintain sinus rhythm, and we intend to explore this possibility.

Short bouts of ventricular fibrillation were observed in 3 patients with atrial fibrillation. All 3 survived and none had the arrhythmia long enough to produce the clinical picture of cardiac arrest. Julian et al. (1964) made a similar observation, but their patients eventually died.

Most authors (Julian et al., 1964; Lawrie et al., 1967) are agreed that multiple arrhythmias carry a poor prognosis and may be very difficult to control. We have been particularly impressed by those patients who develop short bursts of supraventricular or ventricular ectopic beats, and despite vigorous treatment they steadily progress until the patient is having frequent and repeated bouts of ventricular ectopic beats. None of these patients has been shocked, but all have deteriorated inexorably over a period of a week or more, and after several bouts of ventricular tachycardia have progressed to irreversible ventricular fibrillation. No form of treatment from lignocaine to paired pacing (Braunwald et al., 1964) has been more than temporarily effective. We succeeded in keeping only two of them alive by means of large doses of propranolol, but the same regimen failed in those who died. Necropsies were obtained on 4 of the 6 who died, and in all 4 recent occlusions of large branches of both right and left coronary arteries were found.

Bundle-branch block was associated with a high mortality, as in other series (Julian et al., 1964), but right bundle-branch block was much commoner than left. Neither type was particularly associated with anterior or posterior infarction.

\section{SUMMARY}

The incidence and treatment of ventricular arrhythmias in a group of 252 patients observed in an Intensive Coronary Care Unit are discussed. Ventricular arrhythmias were present in 89 patients (35\%).

Ectopic beats were common (28\%), but neither their frequency nor the " $R$ on $T$ " combination necessarily predisposed to ventricular fibrillation. Suppressive therapy should be given to all patients with frequent ectopic beats in order to prevent the haemodynamic disturbance which they cause rather than to avoid the relatively slight risk of ventricular fibrillation. Though lignocaine is often effective, it is not uniformly so and may produce haemodynamic deterioration.

A non-rapid or even slow ventricular ectopic rhythm is not uncommon, and should be suppressed immediately as it is otherwise commonly fatal.

Ventricular tachycardia commonly disappears spontaneously. When persistent it usually responds to lignocaine, but procainamide is also effective without producing significant depression of myocardial contractility.

Ventricular fibrillation, even as a result of a first infarct, without preceding arrhythmias, and in the absence of shock, carries a high mortality (45\%). Immediate DC shock therapy should take precedence over all other forms of treatment.

Attention is drawn to a small but important group of patients with multiple salvoes of supraventricular and ventricular extrasystoles, who are not necessarily shocked but who are often completely resistant to treatment and proceed to fatal ventricular fibrillation. 


\section{REFERENCES}

Balcon, R., Jewitt, D. E., Davies, J. P. H., and Oram, S. (1966). A controlled trial of propranolol in acute myocardial infarction. Lancet, 2, 917.

Braunwald, E., Ross, J., Frommer, P. L., Williams, J. F., Sonnenblick, E. H., and Gault, J. H. (1964). Clinical observations on paired electrical stimulation of the heart. Amer. F. Med., 37, 700.

Fluck, D. C., Olsen, E., Pentecost, B. L., Thomas, M., Fillmore, S. J., Shillingford, J. P., and Mounsey, J. P. D. (1967). Natural history and clinical significance of arrhythmias after acute cardiac infarction. Brit. Heart F., 29, 170.

Gianelly, R., von der Groeben, J. O., Spivack, A. P., and Harrison, D. C. (1967). Effect of lidocaine on ventricular arrhythmias in patients with coronary heart disease. New Engl. F. Med., 277, 1215.

Harris, A., Redwood, D., Davies, M., and Davies, G. (1968). Causes of death in patients with complete heart block and artificial pacemakers. Brit. Heart F., 3014.

Harrison, D. C., Sprouse, J. H., and Morrow, A. G. (1963). Antiarrhythmic properties of lidocaine and procaine amide: clinical and physiologic study of their cardiovascular effects in man. Circulation, 28, 486.

Jewitt, D. E., Balcon, R., Raftery, E. B., and Oram, S. (1967). Incidence and management of supraventricular arrhythmias after acute myocardial infarction. Lancet, 2, 734.
Julian, D. G., Valentine, P. A., and Miller, G. G. (1964). Disturbances of rate, rhythm and conduction in acute myocardial infarction. Amer. F. Med., 37, 915.

Lawrie, D. M., Greenwood, T. W., Goddard, M., Harvey, A. C., Donald, K. W., Julian, D. G., and Oliver, M. F. (1967). A coronary-care unit in the routine management of acute myocardial infarction. Lancet, 2, 109.

-, Higgins, M. R., Godman, M. J., Oliver, M. F., Julian, D. G., and Donald, K. W. (1968). Ventricular fibrillation complicating acute myocardial infarction. Lancet, 2, 523.

Lown, B., Vassaux, C., Hood, W. B., Fakhro, A. M., Kaplinsky, E., and Roberge, G. (1967). Unresolved problems in coronary care. Amer. F. Cardiol., 20, 494.

Meltzer, L. E., and Kitchell, J. B. (1966). The incidence of arrhythmias associated with acute myocardial infarction. Progr. cardiovasc. Dis., 9, 50.

Smirk, F. H., and Palmer, D. G. (1960). A myocardial syndrome, with particular reference to the occurrence of sudden death and of premature systoles interrupting antecedent $\mathrm{T}$ waves. Amer. F. Cardiol., 6, 620.

Spracklen, F. H. N., Kimerling, J. J., Besterman, E. M. M., and Litchfield, J. W. (1968). The use of lignocaine in treatment of cardiac arrhythmias. Brit. med. F., 1, 89.

Stock, E., Goble, A., and Sloman, G. (1967). Assessment of arrhythmias in myocardial infarction. Brit. med. F., 2, 719. 